620.

\title{
CORRECTION OF TWO NUMERICAL ERRORS IN SOHNKE'S PAPER RESPECTING MODULAR EQUATIONS.
}

[From the Journal für die reine und angewandte Mathematik (Crelle), t. LxxxI. (1876), p. 229.]

IN Sohnke's paper "Aequationes modulares pro transformatione functionum ellipticarum," Crelle, t. xvi. (1837), there is, on p. 113, an obvious error in the expression of $u^{6}$, viz. the term $q^{18}$ is given with the same numerical coefficient as it had in $u^{5}$ : this remark was made to me by $\mathrm{Mr}$ W. Barrett Davis, who finds that the term of $u^{6}$ should be

$$
+13569463 q^{18} \text {. }
$$

In the expression of $u^{18}\left(\right.$ l. c., p. 115), I had remarked that, in the coefficient of $q^{16}, \mathrm{a}$ figure must have dropped out. Mr Davis has verified this, and finds that the figure omitted is a 1 in the unit's place, and thus that the correct value* is

$$
+80177033781 q^{16} \text {. }
$$

Cambridge, 26 October, 1875.

* [The former of these numbers should replace the number 15063859 in the Table, p. 128 of this volume; the latter has been introduced in the Table, p. 129.] 